\title{
Cost Minimization Policy for Manufacturer in a Supply Chain Management System with Two Rates of Production under Inflationary Condition
}

\author{
Sujata Saha ${ }^{a *}$, Tripti Chakrabarti ${ }^{b}$ \\ a Department of Mathematics, Mankar College, West Bengal, India \\ Address: Udayan sangha club purba, Mankar, West Bengal 713144, India \\ b Techno India University, West Bengal, India \\ Address: EM-4, EM Block, Sector V, Bidhannagar, Kolkata, West Bengal 700091, India \\ * Corresponding author: sahasujata@outlook.com
}

\section{ARTICLE INFO}

\section{Article history}

Received May 18, 2020

Revised August 21, 2020

Accepted August 23, 2020

Available Online August 30, 2020

Keywords

Two Rates of Production Rate Inflation

Deterioration

Supply Chain Management

Cost Minimization

\begin{abstract}
This article presents a production inventory model for deteriorating goods with two different rates of production. The manufacturer starts manufacturing the items at a lower rate to avoid a huge investment at the initial stage and reduce the products' holding cost. However, when the stock level reaches a prefixed level, he switches on to a higher production rate to avoid shortage caused by an insufficient stock of the items. Moreover, the impact of inflation and the time value of money on the manufacturing system's cost is considered here, which harms any business by reducing the value of an investment with time. We determined the optimum production times at both the low and high production rates by minimizing the system's total cost. Numerical examples illustrated the applicability of this proposed model. Sensitivity analysis studied the effect of changes in the parameters associated with this model on the optimal decision variables. This numerical experiment was done in LINGO 18.0 software. Results showed that the production strategy taken by the manufacturer helped reduce his total cost.
\end{abstract}

This is an open-access article under the CC-BY-SA license.

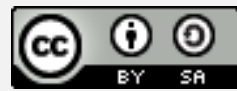

\section{Introduction}

Recently, the marketing or business environment is becoming highly competitive. Most businesses should adopt various strategic and tactical plans to sustain their existence. In this regard, a vital issue for any manufacturing firm is to fix an optimum production rate. A high manufacturing rate harms the business economy by investing huge capital for this process and incurring the holding and deterioration costs. On the other hand, an insufficient stock due to a low producing rate may result in a shortage, incurring penalty cost. Therefore, various authors studied this issue while developing their models. Datta [1] framed an inventory model considering the products' qualitydependent production rate, where the rate decreases when the quality improves. Saha and 
Chakrabarti [2] developed an Economic Production Quantity model (EPQ), assuming that the production rate remains almost constant up to a certain period. After that, the rate decreases due to machinery fault, lethargy, or the personnel for continuous work. Alfares [3] assumed a finite production rate in their model. Another study [4] considered the demand-dependent production rate while developing an EPQ model. This study assumed the demand rate as a linearly increasing function of time; therefore, the producing rate is also a linear function. Roy and Samanta [5] and Bhowmick and Samanta [6] considered the two production rates in an inventory model with deteriorating items. Two studied [7], [8] discussed the constant production rate, which showed a decrease in the inventory system's total cost with the increase in this parameter. Different studies [9] also explained the constant production rate, which finds an increase in the inventory system's joint total profit with the increase in it. Keshavarzfard, et al. [10] framed a production- inventory model where the manufacturer's production rate varies with the power demand rate.

Besides the production rate, another critical factor affecting a company's financial system is inflation and money's time value. Money is losing the purchasing capacity of certain products day by day due to a high rate of inflation [11], [12]. Therefore, it forces one to spend more on buying a product and can reduce the value of an investment. An inventory model developed by Uthayakumar and Palanivel [13] projected the effect of inflation which showed a significant increase in the cycle length, the order quantity, and the total cost with an increase in the net discount rate of inflation. Khurana et al. [14] constructed a production inventory model for deteriorating products, which also showed its adverse effect on the system's total cost. Mondal et. al. [15] developed a production repairing inventory model under an inflationary environment. They formulated this model as an optimal control problem and found a negative impact of inflation on the system's profit. Some other studies [16], [17], [18] also find a rise in the production cost with the increase in the inflation rate.

The deterioration of any product is defined as the damage or the loss of utility partially or fully, resulting in the loss in the marginal value of this item. Most physical goods, such as agricultural products, foods, beverages, and pharmaceuticals goods deteriorate in their normal storage period. Several studies considering the deterioration of products showed that the inventory cost increases with the increase in the deterioration rate [19], [20], [21], [22], [23]. A study by Saha \& Chakrabarti [24] postulated a constant rate of deterioration in their model. Prasad and Mukherjee [25] formulated an inventory model where a two-parameter Weibull distribution has represented the rate of deterioration. Further, Chan et al. [26] framed an integrated production inventory model for exponentially deteriorating items considered the products' deterioration during delivery. Banerjee \& Agrawal [27] studied the optimal discounting and the ordering policies in an inventory system considering the general deterioration distribution. Khakzad \& Gholamian [28] constructed an inventory model for deteriorating products that studied the effect of inspection times during the replenishment period on the deterioration rate. When we model an inventory or supply chain problem, we consider various factors associated with the system. All the strategies aim to minimize the total cost of the inventory or the supply chain system [29], [30], [31].

In this study, we have assumed that the manufacturer starts producing the items at a lower rate to avoid a large stock of products at the initial stage. He switches on to a higher production rate when the inventory level reaches a prefixed level. This strategy may help him to get rid of the holding cost and the deterioration cost of the products and consequently the total cost of the production system. Furthermore, starting at a higher 
rate may block the manufacturer's investment in production for a longer period, then losing the opportunity to earn interest from it. Again, inflation and the time value of money are the other essential factors impacting the economy significantly, and nowadays, it is becoming a permanent feature of the financial system. Therefore, it is crucial to consider this factor while developing a production inventory model. Best known to the authors of this paper, no author considered these issues in their studies. Although two studies by Roy and Samanta [5] and Bhowmick and Samanta [6] considered the two production rates, they did not consider the effect of inflation and the time value of money. Therefore, to address this evidence gap, this study aims to determine the cost minimization policy of a manufacturer producing items that deteriorate over time considering all these issues. We derived the optimum production time by minimizing the total cost of the system. We illustrated the applicability of the proposed model numerically using LINGO 18.0 software. Also, we studied the effect of changes in the parameters on the optimum decision variables. This model may help the manufacturing companies to make production decisions to optimize the total cost of the system.

This paper has been organized in the following sequence. Section 2 presented the notations, assumptions used to formulate the model, mathematical modeling, the solution methodology, numerical examples, and the sensitivity analysis procedure. In addition to that, the results and discussion has been carried out in section 3. Finally, we concluded section 4 .

\section{Methods}

\subsection{Notations and Assumptions}

We used the following notations to formulate the model

$I(t) \quad$ : Inventory level of the manufacturer at time $t$.

a : constant demand rate

$p_{1} \quad$ : production rates started at time $t=0$

$t_{1} \quad$ : Time up to which the production is running at a lower rate $p_{1}$

$p_{2} \quad$ : production rates started at time $t=t_{1}$

$t_{2}$ : Time up to which the production is running at a lower rate $p_{2}$

$\theta \quad$ : constant rate of deterioration.

$Q_{1} \quad$ : Inventory level at time $\mathrm{t}=\mathrm{t}_{1}$

$S \quad$ : Inventory level at time $\mathrm{t}=\mathrm{t}_{2}$

$C_{m} \quad$ : Production cost per unit for the manufacturer

$h_{m} \quad$ : Holding cost per unit time

$d_{m} \quad$ : Deterioration cost per unit

$A_{m} \quad$ : Setup cost per cycle

$r \quad: \delta-i$, where $\delta$ is the interest rate per unit of currency, and $\mathrm{i}$ is the inflation per unit currency.

$T \quad$ : The fixed duration of a production cycle.

$S C \quad$ : Total set-up cost

$P C \quad$ : Total production cost

$H C \quad$ : Total holding cost

$D C \quad$ : Total deterioration cost

$H \quad$ : The determinant value of the Hessian matrix 
$T C_{m}$ : Total cost of the manufacturer

We have formulated this model based on the following assumptions:

i. Demand rate is known, constant, and continuous during the planning horizon under consideration.

ii. There is no repair of deteriorating items during the period.

iii. The production system produces a single item.

iv. The planning horizon is finite.

v. In this model, we have considered the effect of inflation and the time value of money.

vi. Shortages are not allowed.

vii. The rate of deterioration is constant.

The production of the item is started at time $t=0$, at a production rate $p_{1}$ and continues up to time $t=t_{1}$, when the inventory level reaches $Q_{1}$, then the rate of production is switched over to a higher rate $p_{2}$ and the production is stopped when the inventory level reaches S. The inventory depletes due to constant demand (a) and deterioration $(\theta)$ and reaches zero level at time $t=T$.

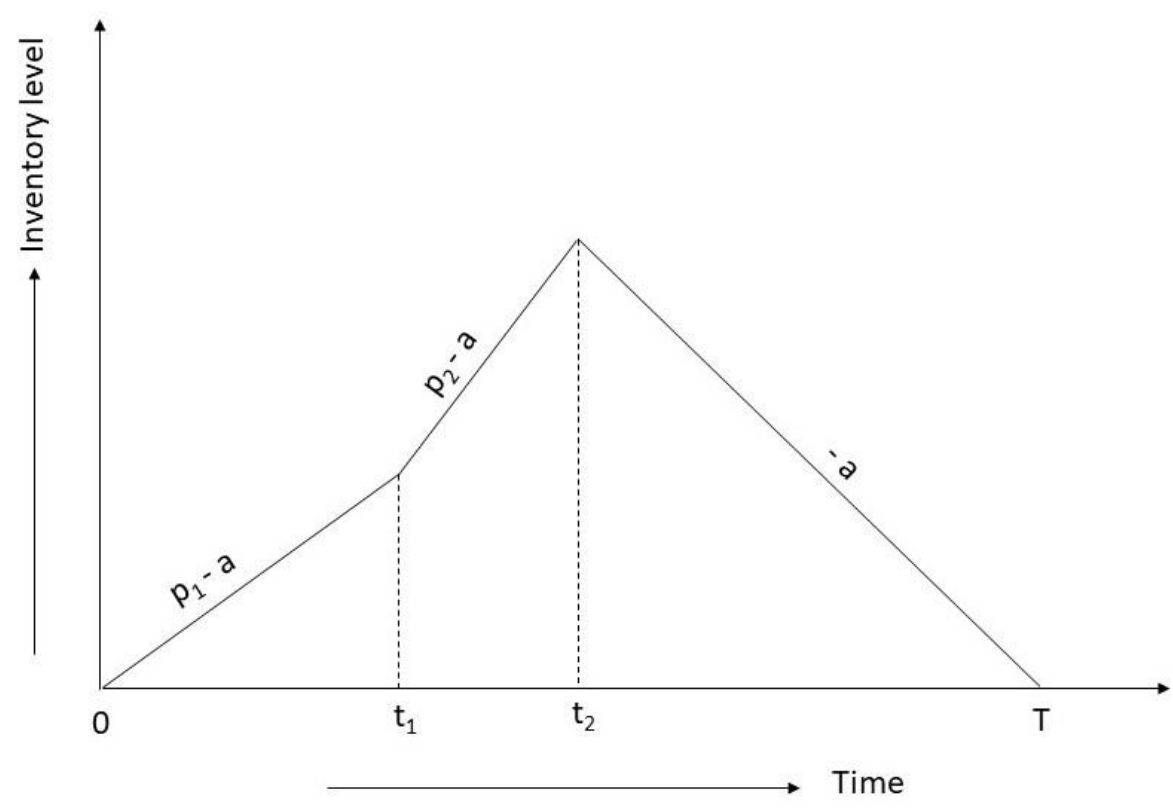

Fig. 1 Pictorial Representation of the Model

\subsection{Mathematical Modeling}

In this section, the mathematical model to derive the cost function of the manufacturer is constructed. The manufacturer starts producing the items at a lower rate $\mathrm{p} 1$ at time $\mathrm{t}=0$ and continues up to time $\mathrm{t}=\mathrm{t} 1$ when his inventory level reaches a prefixed level $\mathrm{Q} 1$. He switches on to a higher production rate $\mathrm{p} 2$ at time $\mathrm{t}=\mathrm{t} 1$ and keeps his manufacturing process up to time $t=t 2$. At this point, his inventory level reaches the highest level S. Afterwards, his inventory level depletes due to customers' demand and the products' deterioration and reaches the zero level at time $t=T$. Fig. 1 represents the pictorial representation of this model. 
Let $I(t)$ be the on-hand inventory at time $t(0 \leq t \leq T)$. Then the differential equations describing the inventory level $I(t)$ in the interval $[0, T]$ are given by the following construct:

$$
\frac{d I(t)}{d t}+\theta I(t)=\left\{\begin{array}{cc}
p_{1}-a, & 0 \leq t \leq t_{1} \\
p_{2}-a, & t 1 \leq t \leq t_{2} \\
-a, & t_{2} \leq t \leq T
\end{array}\right.
$$

With boundary conditions:

$$
I(0)=0, I\left(t_{1}\right)=Q_{1}, I\left(t_{2}\right)=S, I(T)=0
$$

The solutions of the equations (1) are given by

$$
I(t)= \begin{cases}\frac{1}{\theta}\left(p_{1}-a\right)\left(1-e^{-\theta t}\right), & 0 \leq t \leq t_{1} \\ \frac{1}{\theta}\left(\mathrm{p}_{2}-\mathrm{a}\right)+\left[\mathrm{Q}_{1}-\frac{1}{\theta}\left(\mathrm{p}_{2}-\mathrm{a}\right)\right] e^{-\theta\left(t-t_{1}\right)}, & t_{1} \leq t \leq t_{2} \\ -\frac{1}{\theta} \mathrm{a}+\left(\mathrm{S}+\frac{1}{\theta} \mathrm{a}\right) e^{-\theta\left(t-t_{2}\right)}, & t_{2} \leq t \leq T\end{cases}
$$

Using the boundary condition $I\left(t_{1}\right)=Q_{1}$, from (3) we have

$$
Q_{1}=\frac{1}{\theta}\left(p_{1}-a\right)\left(1-e^{-\theta t_{1}}\right)
$$

Again, from the boundary condition $I\left(t_{2}\right)=S$, from (3) we have

i.e.,

$$
0=-\frac{a}{\theta}+\left(S+\frac{a}{\theta}\right) e^{-\theta\left(T-t_{2}\right)}
$$

$$
S=\frac{a}{\theta}\left(e^{\theta\left(T-t_{2}\right)}-1\right)
$$

Now present worth setup cost

$$
S C=A_{m}
$$

Present worth production cost

$$
\begin{array}{r}
P C=C_{m}\left[p_{1} \int_{0}^{t_{1}} e^{-r t} d t+p_{2} \int_{t_{1}}^{t_{2}} e^{-r t} d t\right] \\
=C_{m}\left(-\frac{p_{1}}{r}\left(e^{-r t_{1}}-1\right)-\frac{p_{2}}{r}\left(e^{-r t_{2}}-e^{-r t_{1}}\right)\right) \\
=C_{m} p_{1}\left(t_{1}-\frac{r t_{1}^{2}}{2}\right)+C_{m} p_{2}\left\{\left(t_{2}-t_{1}-\frac{r}{2}\left(t_{2}{ }^{2}-t_{1}{ }^{2}\right)\right\}\right.
\end{array}
$$


Present worth holding cost:

$$
\begin{aligned}
H C & =h_{m}\left[\int_{0}^{t_{1}} I(t) e^{-r t} d t+\int_{t_{1}}^{t_{2}} I(t) e^{-r t} d t+\int_{t_{2}}^{T} I(t) e^{-r t} d t\right] \\
=h_{m}\left[\left(p_{1}-\mathrm{a}\right)\right. & \frac{t_{1}{ }^{2}}{2}+\left(p_{1}-\mathrm{a}\right) t_{1}\left\{\left(t_{2}-t_{1}\right)-\frac{r}{2}\left(t_{2}{ }^{2}-t_{1}{ }^{2}\right)-\frac{\theta}{2}\left(t_{2}-t_{1}\right)^{2}\right\} \\
+ & \frac{1}{2}\left(p_{2}-\mathrm{a}\right)\left(t_{2}-t_{1}\right)^{2}+\mathrm{a} T\left\{-\frac{(r+\theta)}{2}\left(T^{2}-t_{2}^{2}\right)+\left(T-t_{2}\right)^{2}\right\} \\
- & \left.\frac{a}{2}\left(T^{2}-t_{2}^{2}\right)\right]
\end{aligned}
$$

Cost of deteriorated units:

$$
\begin{gathered}
D C=d_{m} \theta\left[\int_{0}^{t_{1}} I(t) e^{-r t} d t+\int_{t_{1}}^{t_{2}} I(t) e^{-r t} d t+\int_{t_{2}}^{T} I(t) e^{-r t} d t\right] \\
=d_{m} \theta\left[\left(p_{1}-\mathrm{a}\right) \frac{t_{1}{ }^{2}}{2}+\left(p_{1}-\mathrm{a}\right) t_{1}\left\{\left(t_{2}-t_{1}\right)-\frac{r}{2}\left(t_{2}{ }^{2}-t_{1}{ }^{2}\right)-\frac{\theta}{2}\left(t_{2}-t_{1}\right)^{2}\right\}\right. \\
+\frac{1}{2}\left(p_{2}-\mathrm{a}\right)\left(t_{2}-t_{1}\right)^{2}+\mathrm{a} T\left\{-\frac{(r+\theta)}{2}\left(T^{2}-t_{2}^{2}\right)+\left(T-t_{2}\right)^{2}\right\} \\
\left.-\frac{a}{2}\left(T^{2}-t_{2}^{2}\right)\right]
\end{gathered}
$$

Present worth total cost:

$$
\begin{aligned}
T C_{m}=S C+P C & +H C+D C \\
& =A_{m}+C_{m} p_{1}\left(t_{1}-\frac{r t_{1}{ }^{2}}{2}\right)+C_{m} p_{2}\left\{\left(t_{2}-t_{1}\right)-\frac{r}{2}\left(t_{2}{ }^{2}-t_{1}{ }^{2}\right)\right\} \\
& +\left(h_{m}+d_{m} \theta\right)\left[\left(p_{1}-\mathrm{a}\right) \frac{t_{1}{ }^{2}}{2}\right. \\
& +\left(p_{1}-\mathrm{a}\right) t_{1}\left\{\left(t_{2}-t_{1}\right)-\frac{r}{2}\left(t_{2}{ }^{2}-t_{1}{ }^{2}\right)-\frac{\theta}{2}\left(t_{2}-t_{1}\right)^{2}\right\} \\
& +\frac{1}{2}\left(p_{2}-\mathrm{a}\right)\left(t_{2}-t_{1}\right)^{2}+\mathrm{a} T\left\{-\frac{(r+\theta)}{2}\left(T^{2}-t_{2}^{2}\right)+\left(T-t_{2}\right)\right\} \\
& \left.-\frac{a}{2}\left(T^{2}-t_{2}^{2}\right)\right]
\end{aligned}
$$

\section{Lemma. The cost function $\left(\mathrm{TC}_{\mathrm{m}}\right)$ of the manufacturer is convex with respect to} $\mathbf{t}_{1}$.

The cost function TCm will be convex with respect to $\mathrm{t} 1$ if its second derivative is greater than zero. Therefore, to examine the convexity of the cost function TCm in equation (10), differentiating it twice with respect to $t_{1}$ we have - 


$$
\begin{aligned}
\frac{\partial\left(T C_{m}\right)}{\partial t_{1}}=C_{m} p_{1} & \left(1-r t_{1}\right)+C_{m} p_{2}\left(-1+r t_{1}\right) \\
& +\left(h_{m}+d_{m} \theta\right)\left[\left(p_{1}-a\right) t_{1}\right. \\
& +\left(p_{1}-a\right)\left\{\left(t_{2}-t_{1}\right)-\frac{r}{2}\left(t_{2}{ }^{2}-t_{1}{ }^{2}\right)-\frac{\theta}{2}\left(t_{2}-t_{1}\right)^{2}\right\} \\
& \left.+\left(p_{1}-\mathrm{a}\right) t_{1}\left\{-1+r t_{1}+\theta\left(t_{2}-t_{1}\right)\right\}-\left(p_{2}-\mathrm{a}\right)\left(t_{2}-t_{1}\right)\right]
\end{aligned}
$$

And,

$$
\begin{gathered}
\frac{\partial^{2}\left(T C_{m}\right)}{\partial t_{1}{ }^{2}}=r C_{m}\left(p_{2}-p_{1}\right)+\left(h_{m}+d_{m} \theta\right)\left[2\left(p_{1}-\mathrm{a}\right)\left\{r t_{1}+\theta\left(t_{2}-t_{1}\right)\right\}+\left(p_{2}-p_{1}\right)\right. \\
\left.+\left(\mathrm{p}_{1}-\mathrm{a}\right) t_{1}(r-\theta)\right]
\end{gathered}
$$

Since $p_{2}>p_{1}, p_{1}>\mathrm{a}, p_{2}>a$ and $t_{2}>t_{1}, \frac{\partial^{2}\left(T C_{m}\right)}{\partial t_{1}{ }^{2}}>0$.

Therefore, $T C_{m}$ is convex with respect to $t_{1}$.

\subsection{Solution Methodology}

In this model, the decision variables are the time $t 1$ and $t 2$. The manufacturer should continue the production at a lower rate $\mathrm{p} 1$ and the higher rate $\mathrm{p} 2$, respectively. Therefore, our purpose is to derive the optimum values of $t 1$ and $t 2$, keeping the total cost of the manufacturer at an optimum (minimum) level. It can be achieved from the necessary condition to minimize the total cost TCm.

Now, the necessary conditions to minimize the cost $\mathrm{TC}_{\mathrm{m}}$ are

$$
\frac{\partial\left(T C_{m}\right)}{\partial t_{1}}=0 \text { and } \frac{\partial\left(T C_{m}\right)}{\partial t_{2}}=0
$$

Therefore, we can get the optimum value of $\mathrm{t} 1$ by equating the right-hand side of equation (11) and that of $\mathrm{t} 2$ from the following equation

$$
\begin{aligned}
\frac{\partial\left(T C_{m}\right)}{\partial t_{2}}=C_{m} p_{2} & \left(1-r t_{2}\right) \\
& +\left(h_{m}\right. \\
& \left.+\theta d_{m}\right)\left[\left(p_{1}-a\right) t_{1}\left\{1-r t_{2}-\theta\left(t_{2}-t_{1}\right)\right\}+\left(p_{2}-a\right)\left(t_{2}-t_{1}\right)\right. \\
& \left.+a T\left\{(r+\theta) t_{2}-1\right\}+a t_{2}\right]=0
\end{aligned}
$$

The values of $\mathrm{t} 1$ and $\mathrm{t} 2$ obtained will optimize the total cost of the manufacturer if these values of $\mathrm{t} 1$ and $\mathrm{t} 2$ satisfy the sufficient conditions -

$\frac{\partial^{2}\left(T C_{m}\right)}{\partial t_{1}{ }^{2}}>0$ and the determinant value of the Hessian matrix $(\mathrm{H})-$ 


$$
\left[\begin{array}{ll}
\frac{\partial^{2}\left(T C_{m}\right)}{\partial t_{1}^{2}} & \frac{\partial^{2}\left(T C_{m}\right)}{\partial t_{1} \partial t_{2}} \\
\frac{\partial^{2}\left(T C_{m}\right)}{\partial t_{1} \partial t_{2}} & \frac{\partial^{2}\left(T C_{m}\right)}{\partial t_{2}^{2}}
\end{array}\right]>0
$$

i.e., if

Now,

$$
H=\frac{\partial^{2}\left(T C_{m}\right)}{\partial t_{1}{ }^{2}} \cdot \frac{\partial^{2}\left(T C_{m}\right)}{\partial t_{2}{ }^{2}}-\left(\frac{\partial^{2}\left(T C_{m}\right)}{\partial t_{1} \partial t_{2}}\right)^{2}>0
$$

$$
\frac{\partial^{2}\left(T C_{m}\right)}{\partial t_{2}^{2}}=-r C_{m} p_{2}+\left(h_{m}+\theta d_{m}\right)\left\{p_{2}+a T(r+\theta)-\left(p_{1}-a\right)(r+\theta) t_{1}\right\}
$$

And,

$$
\frac{\partial^{2}\left(T C_{m}\right)}{\partial t_{1} \partial t_{2}}=\left(h_{m}+\theta d_{m}\right)\left\{\left(p_{1}-p_{2}\right)-\left(p_{1}-a\right)(r+\theta) t_{2}+2\left(p_{1}-a\right) \theta t_{1}\right\}
$$

Therefore, using the equations (12), (14), and (15) we get,

$$
\begin{aligned}
H=\frac{\partial^{2}\left(T C_{m}\right)}{\partial t_{1}{ }^{2}} & \cdot \frac{\partial^{2}\left(T C_{m}\right)}{\partial t_{2}{ }^{2}}-\left(\frac{\partial^{2}\left(T C_{m}\right)}{\partial t_{1} \partial t_{2}}\right)^{2}=r C_{m}\left(p_{2}-p_{1}\right)+\left(h_{m}\right. \\
& \left.+d_{m} \theta\right)\left[2\left(p_{1}-\mathrm{a}\right)\left\{r t_{1}+\theta\left(t_{2}-t_{1}\right)\right\}+\left(p_{2}-p_{1}\right)\right. \\
& \left.+\left(\mathrm{p}_{1}-\mathrm{a}\right) t_{1}(r-\theta)\right] \cdot\left[-r C_{m} p_{2}\right. \\
& +\left(h_{m}+\theta d_{m}\right)\left\{p_{2}+a T(r+\theta)\right. \\
& \left.\left.-\left(p_{1}-a\right)(r+\theta) t_{1}\right\}\right] \\
& -\left[( h _ { m } + \theta d _ { m } ) \left\{\left(p_{1}-p_{2}\right)-\left(p_{1}-a\right)(r+\theta) t_{2}\right.\right. \\
& \left.\left.+2\left(p_{1}-a\right) \theta t_{1}\right\}\right]^{2}
\end{aligned}
$$

We will prove the sufficient condition $(\mathrm{H}>0)$ numerically. Using equation (11) and equation (13), we calculated the optimum values of $\mathrm{t} 1$ and $\mathrm{t} 2$ and the corresponding total cost of the manufacturer in the numerical example section. If the solutions obtained from equations (11) and (13) do not meet sufficient conditions, we may conclude that no feasible solution will be optimal for the set of parameter values. Such a situation will imply that the parameter values are inconsistent, and there are some errors in their estimation. We used LINGO 18.0 software for calculation.

\subsection{Numerical Example}

Example-1: We consider the following numerical values of the parameters in appropriate units to analyze the model

$A_{m}=150 \$, C_{m}=10 \$ /$ unit,$h_{m}=2 \$ /$ unit, $d_{m}=7 \$ /$ unit, $p_{1}=75$ unit per unit of time, $p_{2}=100$ unit per unit of time, $\delta=0.7, \mathrm{i}=0.3, \theta=0.08, \mathrm{~T}=4$ unit of time and a $=70$ unit per unit time. Then we have the values of $t_{1}, t_{2}, Q_{1}, S$ and $T C_{m}$ are respectively $t_{1}=2.57$ unit of time, $t_{2}=3.22$ unit of time, $Q_{1}=11.8$ unit, $\mathrm{S}=56.05$ unit and $T C_{m}=932.11 \$$ in appropriate units. Using these values, we get the determinant value of the Hessian matrix $\mathrm{H}=$ $31087.20>0$. Therefore, these results are optimum. 
In Table 1, we have shown the change of the values of $t_{1}, \mathrm{t}_{2}, Q_{1}, S$ and $T C_{m}$ with the change of the parameters $\theta, r, C_{m}, p_{1}$ and $p_{2}$.

In example 1, if we took $p_{1}=p_{2}=75$ unit per unit of time, we found that the total cost of the system as $T C_{m}=937.09 \$$. Again, if we set $p_{1}=p_{2}=100$ unit per unit time, we found that the total cost of the inventory system was as $T C_{m}=1320.20 \$$. Also, if $p_{1}=$ 100 and $p_{2}=90$ unit per unit of time, then the total cost was $T C_{m}=1335.37 \$$.

Example-2: Consider another inventory system with the following data-

$a_{m}=200 \quad \$, C_{m}=20 \quad \$$ unit, $h_{m}=5 \quad \$ /$ unit, $d_{m}=16 \quad \$ /$ unit, $p_{1}=175 \quad$ unit $/$ day, $p_{2}=200$ unit/day, $\delta=0.7, \mathrm{i}=0.3, \theta=0.08 /$ day, $\mathrm{T}=5$ day , $\mathrm{a}=150$ unit.

Then we have the values of $t_{1}, t_{2}, Q_{1}, S$ and $T C_{m}$ are projected respectively as $\mathrm{t}_{1}=2.65$ days, $t_{2}=4.03$ days, $Q_{1}=59.72$ unit, $\mathrm{S}=151.29$ unit and $T C_{m}=2138 \$$. Here, $\mathrm{H}=1317732$ $>0$, so, these results are optimum.

\subsection{Sensitivity Analysis}

In this section, we carried out a sensitivity analysis to investigate the effect of changes in some parameters $\theta, i, C_{m}, p_{1}$ and $p_{2}$ associated with the model on the optimum decision variables. In practice, the deterioration, inflation, and production cost were found to have an adverse effect on the business economy. Furthermore, in any manufacturing system, the manufacturer needs to fix the production rate and know how the production rate changes impact the production system's cost. Therefore, it is essential to perform this sensitivity analysis. The analysis was done by changing one parameter at a time, keeping the other parameters of the system unchanged.

\section{Results and Discussion}

In the numerical example subsection, we derived the optimum values of the decision variables and the system's total cost considering different production rates. Comparing all these results, it was concluded that the total cost would be minimum if the production unit started producing the items at a lower production rate and switched over to a higher production rate when the inventory level reached a prefixed level. Therefore, we found the production assumption of this model economic for the manufacturer.

This analysis was done based on example 1 . The results of this sensitivity analysis are presented in Table 1. Based on Table 1, we observed that the production time increased slightly with the increase in the deterioration rate $(\theta)$, but the total cost decreased. Similar to the study by Bhowmick and Samanta [6], this study's findings signified a decrease in the stock levels $\mathrm{Q} 1$ and $\mathrm{S}$ with the increase in the deterioration rate. Also, the total cost of the system was susceptible towards the rate of inflation $r$. The production time and the total cost both decreased with the reduction of the inflation rate. This result is quite apparent, and it is similar to the finding of the studies [16], [17], [18]. Furthermore, with the increase in the production cost, the production time decreased. However, the total cost of the system increased, resembling the findings of the study [6]. Moreover, with the increase in the production rate $p_{1}$, the production time at this rate decreased slightly. However, the total cost increased significantly (which is also similar to the study by Bhowmick and Samanta [6]. Therefore, it is wise for the manufacturer to keep the initial production rate as lower as possible. Again, with the increase in the production rate $p_{2}$, the production time and the total cost remain almost static. All in all, the producer can increase the later production rate as higher as needed. 
Table 1 Changes in $t_{1}, t_{2}, Q_{1}, S$ and $T C_{m}$ with the changes of the parameters $\theta, r$, $C_{m}, p_{1}$ and $p_{2}$.

\begin{tabular}{ccccccc}
\hline Parameter & $\begin{array}{c}\text { Parameter } \\
\text { value }\end{array}$ & $\mathrm{t}_{1}$ & $\mathrm{t}_{2}$ & $Q_{1}$ & $\mathrm{~S}$ & $T C_{m}$ \\
\hline$\theta$ & 0.06 & 2.60 & 3.19 & 12.05 & 57.84 & 936.10 \\
& 0.07 & 2.61 & 3.21 & 11.92 & 56.94 & 934.05 \\
& 0.08 & 2.62 & 3.22 & 11.80 & 56.05 & 932.11 \\
& 0.09 & 2.62 & 3.24 & 11.68 & 55.18 & 930.28 \\
$\mathrm{i}$ & 0.1 & 2.63 & 3.25 & 11.55 & 54.33 & 928.56 \\
& 0.30 & 2.62 & 3.22 & 11.80 & 56.05 & 932.11 \\
& 0.25 & 2.40 & 3.08 & 10.90 & 67.12 & 697.37 \\
& 0.20 & 2.22 & 2.96 & 10.15 & 76.03 & 469.96 \\
& 0.15 & 2.06 & 2.86 & 9.51 & 83.38 & 247.45 \\
$C_{m}$ & 0.10 & 1.93 & 2.78 & 8.95 & 89.56 & 28.38 \\
& 8 & 2.67 & 3.32 & 12.03 & 48.54 & 768.32 \\
& 10 & 2.62 & 3.22 & 11.80 & 56.05 & 932.11 \\
& 12 & 2.58 & 3.14 & 11.64 & 62.14 & 1101.03 \\
& 14 & 2.55 & 3.08 & 11.52 & 67.14 & 1273.83 \\
$p_{1}$ & 16 & 2.53 & 3.02 & 11.45 & 71.30 & 1449.34 \\
\hline & 70 & 2.78 & 3.22 & 0.00 & 56.23 & 827.13 \\
& 75 & 2.62 & 3.22 & 11.80 & 56.05 & 932.11 \\
& 80 & 2.46 & 3.23 & 22.31 & 55.88 & 1031.75 \\
& 85 & 2.30 & 3.23 & 31.55 & 55.67 & 1126.35 \\
& 90 & 2.15 & 3.23 & 39.47 & 55.36 & 1216.04 \\
\hline$p_{2}$ & 90 & 2.55 & 3.25 & 11.52 & 53.89 & 937.41 \\
& 95 & 2.59 & 3.24 & 11.69 & 54.99 & 934.82 \\
& 100 & 2.62 & 3.22 & 11.80 & 56.05 & 932.11 \\
& 105 & 2.63 & 3.21 & 11.87 & 57.07 & 929.37 \\
& 110 & 2.64 & 3.20 & 11.92 & 58.06 & 926.65 \\
\hline & & & & & & \\
\hline
\end{tabular}

\section{Conclusion}

In this paper, we have developed a production inventory model for deteriorating items considering the effect of inflation and the time value of money. The initial production rate of the manufacturer was low. However, it switched to a higher production rate at the time when the stock level of the produced commodities reached a prefixed level. We found this strategy economical for the manufacturer. This model might help managers of various industries make production decisions wisely to minimize their production system's total cost. This model can be extended in several ways. Most importantly, researchers can consider the trade credit policy or the manufacturer's quantity discount. Moreover, they may consider various types of production and demand rates.

\section{References}

[1] T. K. Datta, "An Inventory Model with Price and Quality Dependent Demand Where Some Items Produced Are Defective," Advances in Operations Research, vol. 2013, p. 795078, 2013. https://doi.org/10.1155/2013/795078. 
[2] S. Saha and T. Chakrabarti, An EPQ Model for Deteriorating Items with Probabilistic Demand andVariable Production Rate vol. 7, 2018. https://dx.doi.org/10.13140/RG.2.2.32217.36967.

[3] H. K. Alfares, "Production-inventory system with finite production rate, stockdependent demand, and variable holding cost," RAIRO-Oper. Res., vol. 48, pp. 135150, 2014. https://doi.org/10.1051/ro/2013058.

[4] J. Qin, "An EPQ Model with Increasing Demand and Demand Dependent Production Rate under Trade Credit Financing," International Journal of Supply and Operations Management, vol. 2, pp. 532-547, 2015. https://dx.doi.org/10.22034/2015.1.01.

[5] A. Roy and G. P. Samanta, "Inventory model with two rates of production for deteriorating items with permissible delay in payments," International Journal of Systems Science, vol. 42, pp. $1375-1386,2011$. https://doi.org/10.1080/00207721003646256.

[6] J. Bhowmick and G. P. Samanta, "A Deterministic Inventory Model of Deteriorating Items with Two Rates of Production, Shortages, and Variable Production Cycle," ISRN Applied Mathematics, vol. 2011, p. 657464, 2011. https://doi.org/10.5402/2011/657464.

[7] H. Luong and R. Karim, "An integrated production inventory model of deteriorating items subject to random machine breakdown with a stochastic repair time," International Journal of Industrial Engineering Computations, vol. 8, pp. 217-236, 2017. http://dx.doi.org/10.5267/j.ijiec.2016.9.004.

[8] B. K. Mawandiya, J. K. Jha, and J. Thakkar, "Production-inventory model for twoechelon closed-loop supply chain with finite manufacturing and remanufacturing rates," International Journal of Systems Science: Operations \& Logistics, vol. 4, pp. 199-218, 2017. https://doi.org/10.1080/23302674.2015.1121303.

[9] Y. Shen, K. Shen, and C. Yang, "A production inventory model for deteriorating items with collaborative preservation technology investment under carbon tax," Sustainability, vol. 11, p. 5027, 2019. https://doi.org/10.3390/su11185027.

[10] R. Keshavarzfard, A. Makui, and R. Tavakkoli-Moghaddam, "A multi-product pricing and inventory model with production rate proportional to power demand rate," Advances in Production Engineering And Management, vol. 14, pp. 112-124, 2019. https://dx.doi.org/10.14743/apem2019.1.315.

[11] N. Kumar, S. Singh, and R. Kumari, "Learning effect on an inventory model with two-level storage and partial backlogging under inflation," International Journal of Services and Operations Management, vol. 16, pp. 105-122, 2013. https://doi.org/10.1504/IJSOM.2013.055575.

[12] V. Gupta and S. R. Singh, "An integrated inventory model with fuzzy variables, three-parameter Weibull deterioration and variable holding cost under inflation," International Journal of Operational Research, vol. 18, pp. 434-451, 2013. https://doi.org/10.1504/IJOR.2013.057485.

[13] R. Uthayakumar and M. Palanivel, "An inventory model for defective items with trade credit and inflation," Production \& Manufacturing Research, vol. 2, pp. 355379, 2014. https://doi.org/10.1080/21693277.2014.893414.

[14] D. Khurana, S. R. Singh, and S. Tayal, "A Supply Chain Production Inventory Model for Deteriorationg Product with Stock Dependent Demand under Inflationary Environment and Partial Backlogging," International Journal of 


\section{Computer Applications, vol. 131, pp. $\quad 6-12, \quad 2015$.} https://dx.doi.org/10.5120/ijca2015906688.

[15] M. Mondal, A. K. Maity, M. K. Maiti, and M. Maiti, "A production-repairing inventory model with fuzzy rough coefficients under inflation and time value of money," Applied Mathematical Modelling, vol. 37, pp. 3200-3215, 2013. https://doi.org/10.1016/j.apm.2012.07.024.

[16] S. Rani, R. Ali, and A. Agarwal, "Green supply chain inventory model for deteriorating items with variable demand under inflation," International Journal of Business Forecasting and Marketing Intelligence, vol. 3, pp. 50-77, 2017. https://doi.org/10.1504/IJBFMI.2017.082548.

[17] N. Kumar, S. R. Singh, and R. Kumari, "An Inventory Model with Time-Dependent Demand and Limited Storage Facility under Inflation," Advances in Operations Research, vol. 2012, p. 321471, 2012. https://doi.org/10.1155/2012/321471.

[18] M. Palanivel and R. Uthayakumar, "An inventory model with imperfect items, stock dependent demand and permissible delay in payments under inflation," RAIRO-Oper. Res., vol. 50, pp. 473-489, 2016. https://doi.org/10.1051/ro/2015028.

[19] S. Saha, "Fuzzy Inventory Model for Deteriorating Items in a Supply Chain System with Price Dependent Demand and Without Backorder," American Journal of Engineering Research (AJER), vol. 6, 2017.

[20] G. S. Mahapatra, S. Adak, T. K. Mandal, and S. Pal, "Inventory model for deteriorating items with time and reliability dependent demand and partial backorder," International Journal of Operational Research, vol. 29, pp. 344-359, 2017. https://doi.org/10.1504/IJOR.2017.084340.

[21] A. S. Yadav, B. Tyagi, S. Sharma, and A. Swami, "Effect of inflation on a twowarehouse inventory model for deteriorating items with time varying demand and shortages," International Journal of Procurement Management, vol. 10, pp. 761775, 2017. https://doi.org/10.1504/IJPM.2017.087318.

[22] B. Pal, S. S. Sana, and K. Chaudhuri, "A stochastic production inventory model for deteriorating items with products' finite life-cycle," RAIRO-Oper. Res., vol. 51, pp. 669-684, 2017. https://doi.org/10.1051/ro/2016047.

[23] C. K. Sivashankari, "Purchasing Inventory Models for Deteriorating Items with Quadratic Demand," Jurnal Teknik Industri, vol. 20, pp. 204-217, 2019. https://doi.org/10.22219/JTIUMM.Vol20.No2.204-217.

[24] S. Saha and T. Chakrabarti, "Two-echelon Supply Chain Model for Deteriorating Items in an Imperfect Production System with Advertisement and Stock Dependent Demand under Trade Credit," International Journal of Supply and Operations Management, vol. 5, pp. 207-217, 2018. https://dx.doi.org/10.22034/2018.3.5.

[25] K. Prasad and B. Mukherjee, "Optimal inventory model under stock and time dependent demand for time varying deterioration rate with shortages," Annals of Operations Research, vol. 243, pp. 323-334, 2016. https://doi.org/10.1007/s10479014-1759-3.

[26] C. K. Chan, W. H. Wong, A. Langevin, and Y. C. E. Lee, "An integrated productioninventory model for deteriorating items with consideration of optimal production rate and deterioration during delivery," International Journal of Production Economics, vol. 189, pp. 1-13, 2017. https://doi.org/10.1016/j.ijpe.2017.04.001.

[27] S. Banerjee and S. Agrawal, "Inventory model for deteriorating items with freshness and price dependent demand: Optimal discounting and ordering 
policies," Applied Mathematical Modelling, vol. 52, pp. 53-64, 2017. https://doi.org/10.1016/j.apm.2017.07.020.

[28] A. Khakzad and M. R. Gholamian, "The effect of inspection on deterioration rate: An inventory model for deteriorating items with advanced payment," Journal of Cleaner Production, vol. 254, p. 2020. https://doi.org/10.1016/j.jclepro.2020.120117.

[29] S. K. D. B. Maulana, D. M. Utama, M. S. Asrofi, I. S. Ningrum, N. Alba, H. A. Ahfa, et al., "The Capacitated Sustainable EOQ Models: Models Considering Tax Emissions," Jurnal Teknik Industri, vol. 21, pp. 12-21, 2019. https://doi.org/10.22219/JTIUMM.Vol21.No1.12-21.

[30] M. F. Ibrahim and M. M. Putri, "Integrated Green Supply Chain Model to Reduce Carbon Emission with Permissible Delay-in-Payment Consideration," Jurnal $\begin{array}{llllll}\text { Teknik Industri, } & \text { vol. } & 20, & \text { pp. } & 128-139, & \end{array}$ https://doi.org/10.22219/JTIUMM.Vol20.No2.128-139.

[31] S. Saha and T. Chakrabarti, "A supply chain model under return policy considering refurbishment, learning effect and inspection error," Croatian Operational Research Review, vol. 11, pp. 53-66, 2020. https://doi.org/10.17535/crorr.2020.0005. 